\title{
Price competition under cost uncertainty: A laboratory analysis
}

\author{
by KlaUs ABBINK* and JORDI BRANDTS** \\ * $\quad$ University of Nottingham \\ ** Institut d'Anàlisi Econòmica (CSIC), Barcelona
}

November 2002

\begin{abstract}
We study the relation between the number of firms and price-cost margins under price competition with uncertainty about competitors' costs. We present results of an experiment in which two, three and four identical firms repeatedly interact in this environment. In line with the theoretical prediction, market prices decrease with the number of firms, but on average stay above marginal costs. Pricing is less aggressive in duopolies than in triopolies and tetrapolies. However, independently from the number of firms, pricing is more aggressive than in the theoretical equilibrium. Both the absolute and the relative surpluses increase with the number of firms. Total surplus is close to the equilibrium level, since enhanced consumer surplus through lower prices is counteracted by occasional displacements of the most efficient firm in production.
\end{abstract}

\section{Keywords}

Laboratory experiments, industrial organisation, oligopoly, price competition

\section{JEL Classification Codes}

C90, C72, D43, D83, L13

\section{Acknowledgements}

Financial support by the European Union through the TMR research network ENDEAR (FMRX-CT98-0238), the Spanish Ministerio de Educación y Cultura (PB98-0465), and the University of Nottingham is gratefully acknowledged.

\section{Authors}

\begin{tabular}{ll}
\hline \multicolumn{1}{c}{ Klaus Abbink } & \multicolumn{1}{c}{ Jordi Brandts } \\
\hline School of Economics & Institut d'Anàlisi Econòmica (CSIC) \\
The University of Nottingham & Campus UAB \\
University Park & 08193 Bellaterra \\
Nottingham, NG7 2RD & Spain \\
United Kingdom & \\
Phone +44-115-9514768 & Phone $+34-93-5806612$ \\
Fax +44-115-9514591 & Fax $+34-93-5801452$ \\
klaus.abbink@ nottingham.ac.uk & jordi.brandts@uab.es \\
\hline
\end{tabular}




\section{Introduction}

In markets with posted price competition sellers independently choose prices, which are publicly communicated to buyers on a take-it-or-leave-it basis. Such posted pricing is common in retail markets as well as in industries in which regulatory agencies require that prices be filed with them and that discounts not be granted. This type of competition has been studied both theoretically and experimentally. The theoretical work by Bertrand (1883) gave rise to what is known as the Bertrand paradox: If marginal costs are constant then two firms are enough for equilibrium prices to equal marginal cost. Subsequent theoretical work has consisted in proposing price competition models which "resolved" this paradox. Vives (1999) discusses the theoretical work on price competition in detail.

Early experimental work on posted prices, like that of Williams (1973) and Plott and Smith (1978), was not based on formal models of price competition. Instead, it took the Walrasian outcome as the natural benchmark for evaluating behaviour. More recently, a number of experimental studies have investigated price competition on the basis of designs closely connected to theoretical models. Holt (1995) surveys the experimental research on posted prices.

Davis and Holt (1994) and Kruse, Rassenti, Reynolds, and Smith (1994) study price competition in environments in which the equilibrium prediction involves a price distribution with average prices above marginal cost in the spirit of the first theoretical resolution of the Bertrand paradox proposed by Edgeworth (1925). Both studies find price dispersion distinct but qualitatively similar to those predicted by Nash equilibrium. The study by Morgan, Orzen, and Sefton (2001) experimentally examines a model on price competition with informed and uninformed consumers. Informed consumers search for the best price, but uninformed consumers are captive to a firm. As a result, pure strategy equilibria do not exist. The authors find observed price distributions to be different from the prediction, but the comparative statics of the strategic equilibrium to be supported.

One of the central themes of the economic analysis of oligopoly is how the number of firms affects prices when there are only few competitors in the market. Dufwenberg and Gneezy (2000) address this question in what can be seen as the first direct test of the Bertrand paradox as such. They study the effects of market concentration in a one-shot price competition framework with constant marginal cost and inelastic demand. In their experiments, price is above marginal cost for the case of two firms but equal to that cost for three and four firms. ${ }^{1}$ In their results two firms are not enough to get prices down to marginal cost but three firms are. In a sense, the Bernard paradox remains, since the experimental results do not exhibit the intuitively expected negative relation between the number of firms and the price-cost margin.

\footnotetext{
${ }^{1}$ With duopolies, Dufwenberg, Gneezy, Goeree, and Nagel (2002) find that the introduction of price floors (the minimum feasible price is above marginal costs) lead to lower average prices compared to the standard Bertrand game. Thus, the exception for the two-firm case is weakened when price floors are introduced.
} 
Selten and Apesteguía (2002) experimentally study price competition in a model of spatial competition. Their setting involves positive profit margins in the Cournot equilibrium, but these margins are constant in the number of firms. In line with this prediction, they find very little difference in average prices across their treatments with three, four, and five firms, and average prices are close to, but slightly above those chosen in equilibrium.

Abbink and Brandts (2002) examine the effects of the number of firms in an experimental design in which price competition can lead to positive equilibrium price-cost margins. Their design is based on the theoretical model by Dastidar (1995) in which there are multiple equilibria in pure strategies, compatible with price-cost margins being decreasing in the number of firms. Firms operate under decreasing returns to scale and have to serve the whole market. The experimental results are that average prices indeed decrease with the number of firms, but this effect can mainly be attributed to the declining prevalence of collusion. The most frequent market price is one that is reached by a simple imitation dynamic, and this price is invariant to the number of firms.

We present an experimental study based on another theoretical proposal to resolve the Bertrand paradox. Spulber (1995) analyses an extension of the standard Bertrand model in which marginal costs are not common knowledge among the competitors. Rather, they are, for each firm independently, drawn from a distribution and private information for the individual firms. This is an a priori very appealing model, since it is quite natural to consider that firms only have approximate information about rivals' costs.

This incomplete information about costs changes the equilibrium prediction dramatically: Prices are now set substantially above marginal costs. The realised market prices will depend on the random draws, but in expectation prices decrease with the number of firms so that a sufficient increase of the number of firms implies a prediction of lower prices. The equilibrium prediction is in pure, not in mixed strategies.

With our work we wish to contribute to delineating a more complete picture of price competition from an experimental viewpoint. In particular, we are interested in what price and efficiency levels arise and how they depend on the number of firms. With respect to price levels we are interested in finding out whether prices remain above Walrasian levels with three or four firms.

Numerous studies report results on related issues from quantity competition environments. Huck, Normann and Oechssler $(1999,2001)$ provide results and a recent survey of work on the effects of market concentration under repeated quantity competition. ${ }^{2}$ Their conclusion is that duopolists sometimes manage to collude, but that in markets with more than three firms collusion is difficult. With exactly three firms, Offerman, Potters, and Sonnemans (2002) observe that market outcomes depend on the information environment: Firms collude when they

\footnotetext{
${ }^{2}$ Huck, Konrad, Müller, and Normann (2002) study market outcomes when the number of firms decreases through mergers. They find that merged firms produce significantly more than firms without a merger history.
} 
are provided with information on individual quantities, but not individual profits. In many instances, total average output exceeds the Nash prediction and furthermore, these deviations are increasing in the number of firms. The price-cost margins found in experimental repeated quantity competition are, hence, qualitatively consistent with the Cournot prediction for the static game.

Our results show that, in accordance with Spulber (1995), market prices indeed decrease significantly with the number of firms, but - on average - always stay above marginal costs. In this sense, our results back the theoretical resolution of the Bertrand paradox. However, compared to the equilibrium prediction, prices tend to be lower in all treatments. This is good news for consumers, but it does not lift total surplus beyond the level that would result from equilibrium play. Rather, observed surplus and predicted total surplus are very close to one another. The reason is that efficiency gains from closer to marginal cost pricing are cancelled out by occasional displacements, i.e. by quantities produced by firms other than the one with the lowest costs. In relation to the highest possible surplus the actual surplus increases with the number of firms.

\section{The model and the experimental design}

\subsection{The model}

In our experimental markets the demand function is linear with a slope of 1 , in order to choose the simplest formulation of such a function. We chose an inverse demand function

$$
p=99-Q
$$

for our study, where $Q$ is the total quantity demanded. ${ }^{3}$ Each firm $i$ 's cost function is linear with constant marginal $\operatorname{costs} c_{i}$, where the level of $c_{i}$ is randomly drawn from a uniform distribution on the interval $[0,99]$ and is only known by that firm. The interval covers the entire range from zero to the prohibitive price. By choosing such a wide range we focus on an environment in which the effect of cost uncertainty is most pronounced. The random draws for each firm are independent from one another. There are no fixed costs.

Firms set their prices simultaneously. Therefore, no firm knows the choice of any other firm when setting its own price. As in the standard Bertrand model, only firms setting the lowest price produce. If one firm sets the lowest price alone, it serves all demand at that price, if two or more firms set a common lowest price, each of them sells an equal share of that demand. There are no capacity constraints, each firm can (and must) always serve its entire demand.

A firm's strategy assigns a price to any possible realisation of the cost parameter. In equilibrium, firms set prices increasing in their cost parameters and substantially above marginal

\footnotetext{
${ }^{3}$ The intersect of 99 was chosen for practical reasons. In the experiment, subjects only needed to choose between all numbers with up to two digits.
} 
costs. The reason why price competition does not drive equilibrium prices down to marginal costs is intuitive: Upward deviations from the firm's marginal costs will not necessarily result in the loss of all demand, since it is possible that the competitors' costs and prices are higher than the own ones. Rather, the firm faces a trade-off: By increasing its mark-up on its marginal costs, it will increase its profit in the case that its price is still the lowest. The probability of winning the market, on the other hand, becomes smaller the higher the firm sets its markup. The strategic situation is similar to that faced by a bidder in a first-price auction with independent private values: In such an auction, bidders' values for an item on auction are independently drawn from a common distribution, where only the own valuation is known to a bidder when making his bid. Spulber (1995) makes extensive use of this analogy and characterises the equilibria of Bertrand competition with private cost information using techniques developed for auction theory.

Spulber (1995) analyses the properties of the equilibrium prediction for a very general model of this kind. While the general case involves some complexity, the equilibrium price functions for the symmetric case with linear demand are straightforward to compute. ${ }^{4}$ A firm maximises its expected profit by setting the price $p$ as a linear function of the cost parameter $c$ as

$$
p(c) ? \frac{99 ? n c}{1 ? n} .
$$

For a given $n$, the equilibrium price function is linear in the cost parameter, but not proportional to it. If the costs are zero, the firm will charge a high mark- up to maximise its expected profit. If the costs are maximal, however, the firm sets a price equal to its marginal costs. Figure 1 depicts the equilibrium price functions for $n=2, n=3$, and $n=4$.

\subsection{The conduct of the experiment}

The experiment was conducted at the Centre for Decision Research and Experimental Economics (CeDEx) of the University of Nottingham. The software for the experiment was developed using the RatImage programming package (Abbink and Sadrieh (1995)). Subjects were recruited by e-mail from a database of students, who had previously registered at CeDEx to express their willingness in participating in experiments. Each subject was allowed to participate in only one session, and no subject had participated in experiments similar to the present one. The subjects were undergraduate students from a wide range of disciplines.

In our experimental sessions subjects interacted in fixed groups of 2, 3 or 4 for 50 identical rounds. At the beginning of the round, the unit cost parameter was drawn randomly, visualised by a "one-armed bandit" on the terminal's computer screen. The computer drew random numbers for each round and each individual independently; we did not use controlled lottery outcomes. Since the treatments involve a different number of firms and thus a different num-

\footnotetext{
${ }^{4}$ See Wolfstetter (1997:407ff.). When using the term "equilibrium", we always refer to the equilibrium prediction for risk-neutral firms.
} 
ber of random draws in each round, it is not possible to use the same set of realisations for all treatments. The use of completely independent draws creates some sampling variation, as subjects in different treatments observe different samples of cost parameters. However, since we conducted sessions with 50 rounds and a large number of independent markets, such effects do not affect the comparability of our treatments substantially.

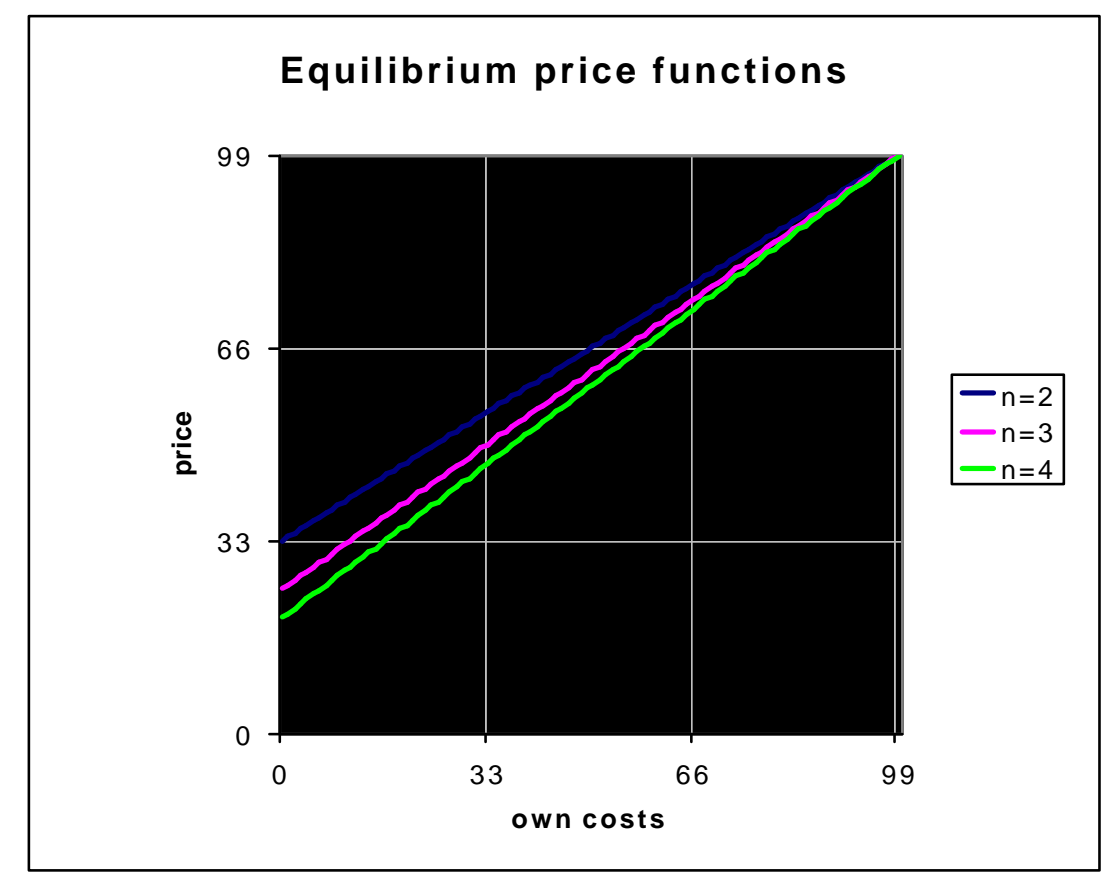

Figure 1

Once the cost parameter was drawn, each subject had to choose a price between 0 and 99 talers (the fictitious experimental currency) per unit. For convenience, cost parameters and price choices were restricted to integers. After each round each subject was informed about the prices chosen by each of the other subjects in the market as well as about all subjects' sales quantities. As in actual markets prices are typically publicly announced, but cost information is kept private, we did not inform subjects about their competitors' cost parameters even after the round. Consequently, subjects were told only their own revenue, costs and profit.

The same subjects played in the same market throughout the session to reflect the repeated game character of actual oligopoly markets. Thus, our setting can be seen as a stylised model of an oligopoly in which firms face strong fluctuations of costs, e.g. caused by changing natural factors. Subjects were not told with whom of the other participants they were in the same group.

To accommodate some losses, subjects were granted a capital balance of 3000 talers at the outset of each session. ${ }^{5}$ The total earnings of a subject from participating in this experiment

\footnotetext{
${ }^{5}$ If this capital balance was used up, the participant was "bankrupt" and the remaining subjects in that market played in a smaller market. Because this creates a very different market environment, we did not use observa-
} 
were equal to his capital balance plus the sum of all the profits he made during the experiment minus the sum of his losses. A session lasted for about 75 minutes (this includes the time spent to read the instructions). At the end of the experiment, subjects were paid their total earnings anonymously in cash, at a conversion rate of one British pound for $2000(n=2)$, $1250(n=3)$ and $1000(n=4)$ talers. Subjects earned between $£ 6.13$ and $£ 21.20$ with an average of $£ 11.26$, which is considerably more than students' regular wage in Nottingham. ${ }^{6}$ At the time of the experiment, the exchange rate to other major currencies was approximately US$\$ 1.50$ and EUR 1.50 for one pound.

We conducted two sessions with 10 and 14 subjects for $n=2$, two sessions with 12 and 15 subjects for $n=3$, and three sessions with 20,16, and 16 subjects for $n=4{ }^{7}$ Subjects interact with each other within groups but not across groups so that each group can be considered as a statistically independent observation. Thus, we gathered 12 independent observations for $n=2,9$ independent observations for $n=3$, and 11 independent observations for $n=4$.

Our analysis primarily consists of nonparametric tests performed on these data points. Most analyses comprise of pairwise comparisons of the treatments. For these we use Fisher's twosample randomisation test, applied to test statistics (e.g. average prices or surplus levels) from the independent observations. ${ }^{8}$ In some occasions we also apply tests to statistics within one sample, as e.g. when comparing our observations to the equilibrium prediction. In this case, we use the nonparametric binomial test. The choice of the test methods used in the following was made before the experiment was conducted.

\section{Results}

\subsection{Average prices and the number of firms}

The three treatments of our experiment allow us to study the effect of market concentration on market outcomes. In particular, we can analyse whether an increase in the number of competitors results in lower transaction or market prices. Table 1 indicates that, on average, this is the case. The table shows average market prices, i.e. the lowest of chosen prices, for the different groups over the 50 rounds of the experiment, ordered from the lowest to the highest for each value of $n$. Average prices are decreasing in the number of firms. Fisher's two-sample randomisation test rejects the null hypothesis of equal average prices at a significance level of

\footnotetext{
tions with bankruptcies in our data analysis. Overall, two participants went bankrupt. Losses can occur if subjects charge prices below their unit costs.

${ }^{6}$ These figures do not include the two participants who went bankrupt. They received a show-up fee of $£ 3$.

${ }^{7}$ The show-up rate for the sessions was quite erratic. Therefore, the number of participants was different across sessions.

${ }^{8}$ This test can be seen as a non-parametric variant of the t-test, with which differences in the mean of two samples can be detected. For a discussion of the power of this test see Moir (1998).
} 
$?=0.005$ (two-sided) for all pairwise comparisons of treatments. Therefore, our results provide qualitative support for the equilibrium prediction of expected prices decreasing with $n$.

Table 1: Average market prices

\begin{tabular}{cccc}
\hline Group No. & $n=2$ & $n=3$ & $n=4$ \\
\hline 1 & 35.80 & 29.58 & 25.02 \\
2 & 40.40 & 32.26 & 25.52 \\
3 & 42.80 & 33.16 & 26.28 \\
4 & 42.88 & 34.94 & 26.52 \\
5 & 49.20 & 35.14 & 27.68 \\
6 & 51.08 & 36.64 & 28.66 \\
7 & 51.24 & 37.26 & 29.08 \\
8 & 51.38 & 37.88 & 33.56 \\
9 & 51.64 & 38.68 & 33.72 \\
10 & 51.64 & & 35.10 \\
11 & 57.28 & & 35.48 \\
12 & 57.82 & & \\
\hline Average & 48.60 & 35.06 & 29.69 \\
\hline Equilibrium ${ }^{9}$ & 53.70 & 43.02 & 35.87 \\
\hline
\end{tabular}

The question arises whether prices tend to increase or decrease over the fifty rounds of the experiment. Figure 2 shows the evolution of average prices, for each round averaged over all markets within a treatment. Visually, the diagram does not strongly suggest any tendency in either direction.

To test for trends statistically, we use the following method. We compute, for each session separately, non-parametric Spearman rank correlation coefficients between the market price and the round number. Using these as summary statistics, we apply the binomial test to detect a systematic tendency to rising or falling prices. The binomial test rejects the null hypothesis at a one-sided $5 \%$ level if at least 10 out of 12 observations for duopolies, 8 out of 9 observations for triopolies, and 9 out of 11 observations for tetrapolies point in the same direction. Table 2 shows the outcome of this analysis. In none of the treatments, the null hypothesis of no trend can be rejected. ${ }^{10}$

\footnotetext{
${ }^{9}$ In all of the following analysis, the equilibrium predictions we note are based on the unit costs actually drawn in the experiment.

${ }^{10}$ The detection of trends is relatively hard in our experiment, as unit costs vary much over time. Thus prices are naturally very volatile. There is no straightforward way to normalise the prices, as mark-ups on them are not independent from cost levels either. However, since our analysis entails 50 rounds, even weak trends in a market should make it likely that a positive or negative Spearman rank correlation coefficient would show up. Notice that our method does not require the individual coefficients to be significant, as they are only used as summary statistics for the binomial test.
} 


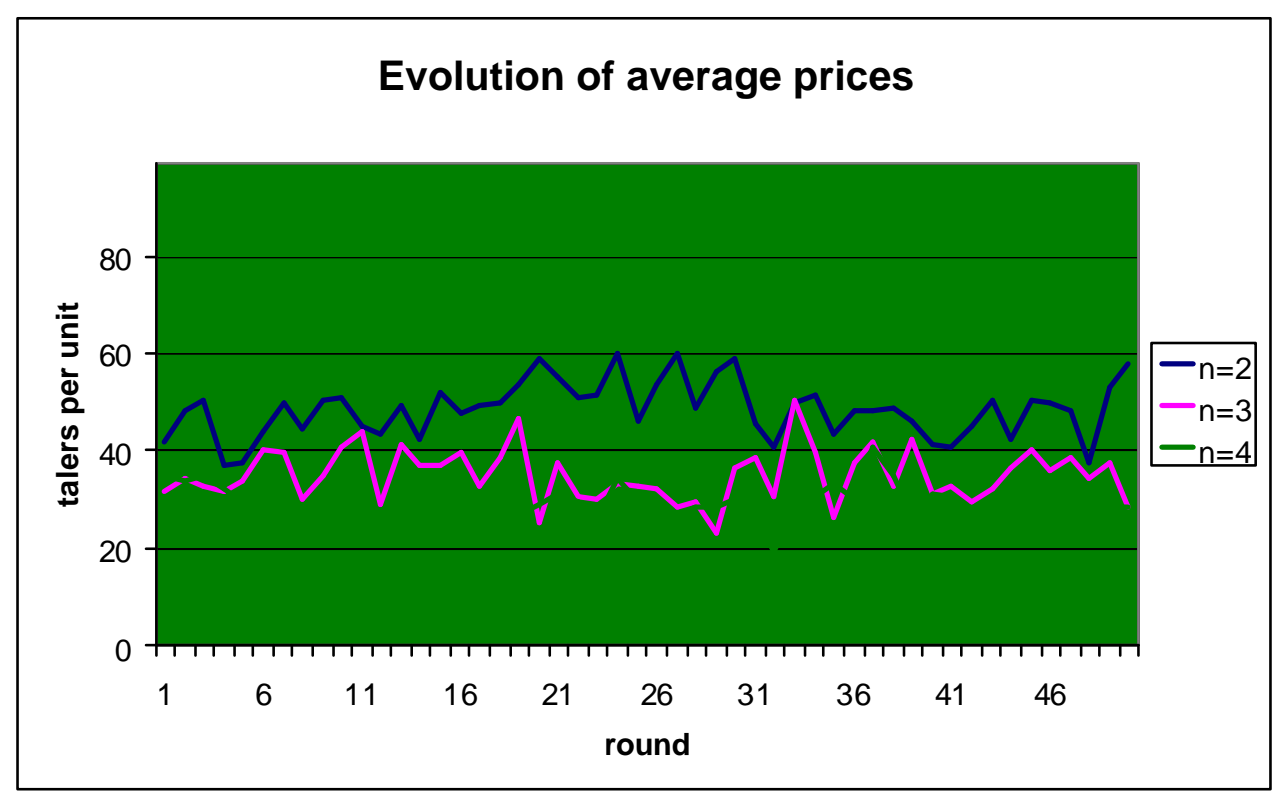

Figure 2

Table 2: Correlation between round number and market price

\begin{tabular}{lcccc}
\hline \multicolumn{1}{c}{$\begin{array}{c}\text { Spearman rank } \\
\text { correlation coefficient }\end{array}$} & $n=2$ & $n=3$ & $n=4$ & Total \\
\hline positive & 7 & 3 & 6 & 16 \\
negative & 5 & 6 & 5 & 16 \\
\hline Total & 12 & 9 & 11 & 32 \\
\hline
\end{tabular}

\subsection{Asking prices}

The above results clearly indicate that average prices tend to decrease with the number of firms. There are two possible causes for this effect. First, more aggressive pricing behaviour could be prevalent in larger markets. This would naturally lead to lower average market prices. However, even if price setting behaviour were the same across treatments, we would observe the phenomenon of decreasing market prices. This is because the market price is the minimum of the $n$ asking prices. Given identical price functions, the lowest of four asking prices would be lower on average than the lowest of three or two asking prices.

Table 3 shows average asking prices, i.e. the average of all chosen prices, for the different groups over the 50 rounds of the experiment, ordered from the lowest to the highest for each value of $n$. The table shows that duopolists ask for considerably higher prices than both triopolists and tetrapolists, but the difference between triopolies and tetrapolies is only marginal. In fact, Fisher's two-sample randomisation test rejects the null hypothesis of equal average asking prices for the comparison of both $n=2$ versus $n=3$ and $n=2$ versus $n=4$ at a signifi- 
cance level of $?=0.005$ (one-sided), while the comparison of $n=3$ versus $n=4$ is not significant (one-tail $p=0.29$ ). Thus, increasing the number of firms from two to three induces significantly more aggressive pricing behaviour, while increasing the number of competitors further to four firms has no significant effect on the mark-ups charged by the firms. The effect on prices, therefore, then stems from the effect that the minimum of the competitors' unit costs tends to be lower with more firms.

Table 3: Average asking prices

\begin{tabular}{cccc}
\hline Group No. & $n=2$ & $n=3$ & $n=4$ \\
\hline 1 & 53.69 & 51.55 & 48.08 \\
2 & 56.07 & 53.19 & 51.35 \\
3 & 57.31 & 55.66 & 51.49 \\
4 & 57.83 & 55.89 & 53.01 \\
5 & 62.30 & 55.99 & 55.31 \\
6 & 62.48 & 57.14 & 55.37 \\
7 & 63.42 & 57.17 & 55.47 \\
8 & 63.49 & 58.44 & 58.14 \\
9 & 63.74 & 58.89 & 58.29 \\
10 & 64.93 & & 59.90 \\
11 & 65.68 & & 60.14 \\
12 & 68.61 & & \\
\hline Average & 61.63 & 55.99 & 55.14 \\
\hline Equilibrium & 65.25 & 61.45 & 59.19 \\
\hline
\end{tabular}

An additional perspective on different pricing behaviour across treatments can be obtained in the following way. Estimate a linear regression for each subject's pricing function. Then take the resulting intercepts and focus on the comparison of the distributions of the intercepts across treatments. Figure 4 shows the three corresponding cumulative distributions and one can see that the differences between $n=4$ and the other two cases are quite substantial, whereas the two distributions for $n=3$ and $n=4$ are rather alike.

\subsection{Pricing behaviour as compared with the theoretical prediction}

The bottom row of tables 1 and 3 indicate the equilibrium prediction of market prices and asking prices. The comparison of observed averages with the equilibrium averages already suggests that experimental firms tend to price more aggressively than predicted in equilibrium. Figure 5 shows all the prices that have been asked in the three treatments, plotted against the corresponding unit costs. In addition, two benchmarks have been drawn into the figures: The diagonal line depicts Walrasian prices, equal to marginal (unit) costs, which lead to zero profits for the firm serving the market. The second line, above the zero-profit line, is the equilibrium prediction for the case of risk-neutrality. 


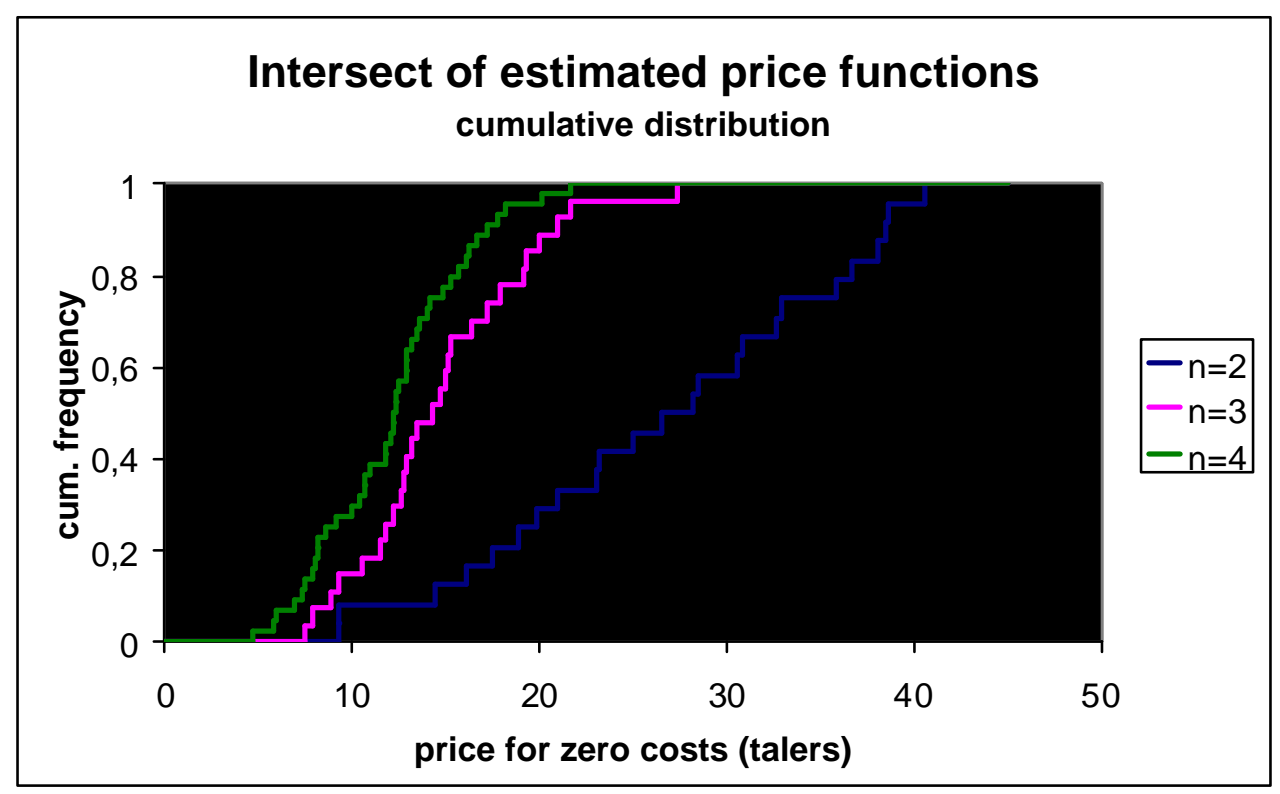

Figure 4

It can be seen that in fact the majority of asking prices are in between the equilibrium prediction and the marginal cost pricing line. The prices charged by the firms do contain a mark-up on the marginal costs, but this mark-up is substantially lower than predicted in equilibrium. ${ }^{11}$ Table 4 shows the number of asking prices that are above, equal to, and below the equilibrium prediction.

Table 4: Asking prices compared to the equilibrium prediction

\begin{tabular}{lrrr}
\hline \multicolumn{1}{c}{ Asking price } & \multicolumn{3}{c}{ Treatment } \\
\multicolumn{1}{c}{ as compared to equilibrium } & $n=2$ & $n=3$ & $n=4$ \\
\hline Above equilibrium & $30.4 \%$ & $14.9 \%$ & $17.8 \%$ \\
as in equilibrium & $3.6 \%$ & $2.6 \%$ & $2.0 \%$ \\
below equilibrium & $66.0 \%$ & $82.5 \%$ & $80.1 \%$ \\
\hline
\end{tabular}

The table indicates that the underpricing, as compared to equilibrium, is less pronounced in duopolies than in the markets with more firms. Broken down to individual markets, we can observe more asking prices below than above the equilibrium prediction in all 9 markets with three and all 11 markets with four firms. For duopolies, this is the case for only 8 of the 12

\footnotetext{
${ }^{11}$ This is reminiscent of a phenomenon observed in independent private value auction experiments (see Kagel (1995)). In that context buyers were observed to bid above the equilibrium prediction for risk-neutrality, which corresponds to below equilibrium pricing in our model. Several explanations of this fact have been suggested, among them non-linear utility, non-linear probability weighting and buyers enjoying the fact of winning as such.
} 
markets, while in 4 markets more prices above than below equilibrium can be observed. ${ }^{12} \mathrm{~A}$ possible explanation is that with two firms, participants may attempt to collude in order to establish higher and more profitable prices. This seems relatively easier in duopolies than in larger markets, as co-ordination requirements are less. However, it is generally hard to establish successful co-operation in the present model. Firms can only observe the prices set by their competitors, but not the costs. The competitors' prices, however, will depend on their costs, such that attempts to signal one's willingness to co-operate are hard to transmit, as the prices are difficult to interpret in that way. As a result, pricing is still quite aggressive even in duopolies. $^{13}$

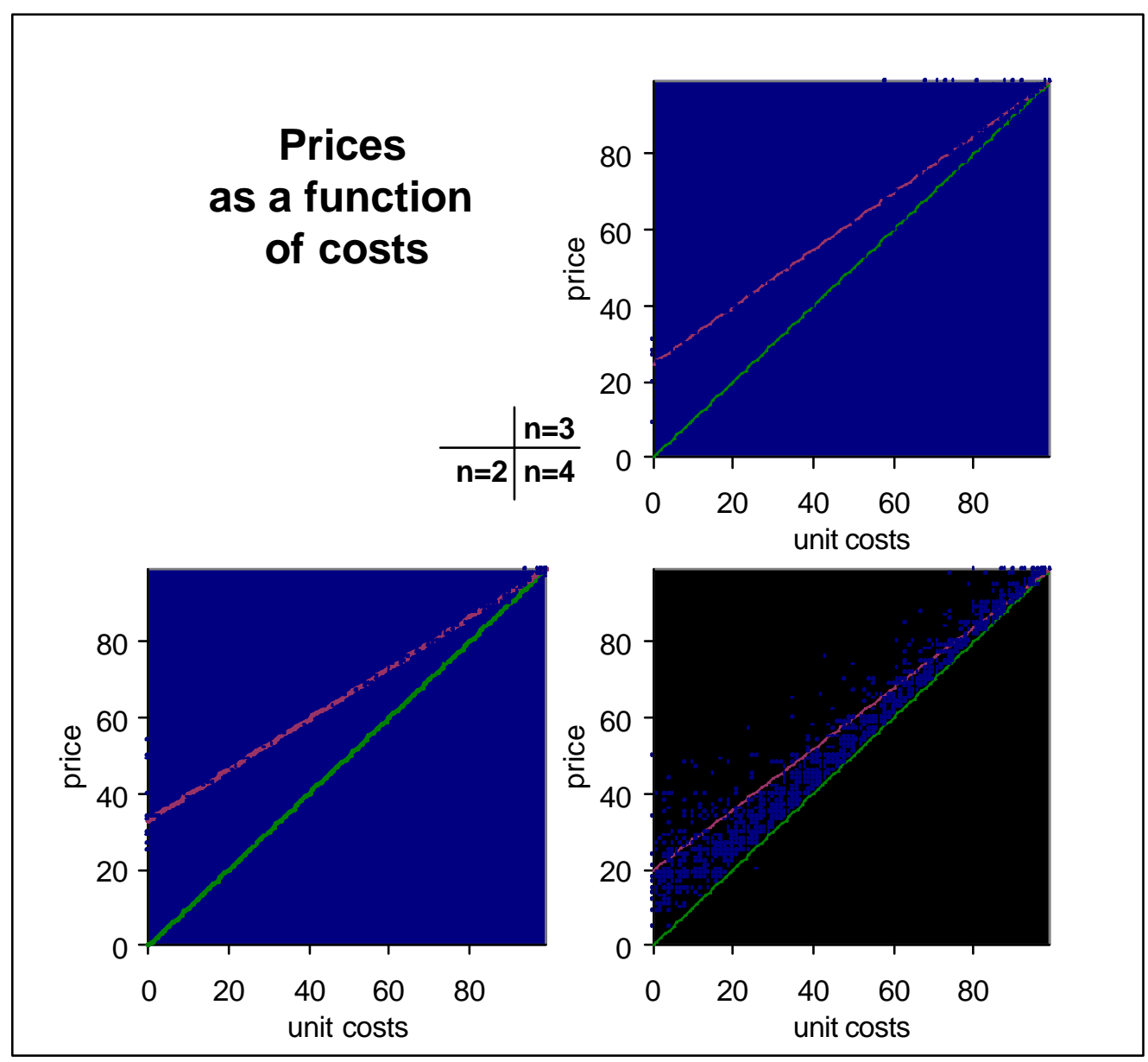

Figure 5

\footnotetext{
${ }^{12}$ If we test the null hypothesis that deviations in both directions are equally likely, the binomial test rejects the null hypothesis for both the $\mathrm{n}=3$ and the $\mathrm{n}=4$ treatment at a significance level of $?=0.005$ (one-sided), while for duopolies the effect is not significant.

${ }^{13}$ The observation that duopolists tend to collude while firms in larger markets do less so has been found in a number of oligopoly experiments on different models, e.g. Huck, Normann, and Oechssler (2001), or Abbink and Brandts (2002).
} 


\subsection{Efficiency}

The three treatments of our experiment enable us to compare efficiency levels for different degrees of market concentration. Below we present information on both absolute and relative efficiency. The measure for efficiency we look at is the total surplus, conventionally defined as the sum of consumer and producer surplus. This would be maximised if (1) the good is produced by the firm with the lowest unit costs, and (2) the market price equals the unit costs of this firm. ${ }^{14}$ Table 5 shows average total surplus - in talers - for the different groups over the 50 rounds of the experiment, ordered from the lowest to the highest for each value of $n$.

Table 5. Average total surplus in the individual markets

\begin{tabular}{cccc}
\hline Group No. & $\mathrm{n}=2$ & $\mathrm{n}=3$ & $\mathrm{n}=4$ \\
\hline 1 & 1856 & 2596 & 2752 \\
2 & 2045 & 2634 & 2800 \\
3 & 2154 & 2713 & 2861 \\
4 & 2215 & 2714 & 2896 \\
5 & 2229 & 2795 & 3043 \\
6 & 2240 & 2813 & 3149 \\
7 & 2376 & 2910 & 3242 \\
8 & 2392 & 2965 & 3295 \\
9 & 2443 & 3235 & 3342 \\
10 & 2525 & & 3405 \\
11 & 2622 & & 3420 \\
12 & 2657 & & \\
\hline Average & 2313 & 2819 & 3109 \\
\hline Equilibrium & 2289 & 2790 & 3109 \\
\hline
\end{tabular}

The absolute total surplus does not account for the fact that larger markets exhibit a greater potential for generating surplus, as the expected minimum costs are lower. Therefore, we also compute relative total surplus as the ratio between attained and maximal total surplus. The results appear in table 6 . The table shows that in all treatments most of the possible surplus is extracted from the market, where duopolies perform somewhat worse than oligopolies with more than two firms. Moving from two to three firms induces a larger increase in surplus extraction than increasing the number further from three to four firms. However, all differences including the latter are significant at $?=0.01$ (one-sided) or lower, according to Fisher's twosample randomisation test. The fact that relative efficiency increases with the number of firms indicates that the absolute efficiency advantage of more firms is not only induced by the greater potential of generating surplus, which stems from the fact that the lowest unit cost is

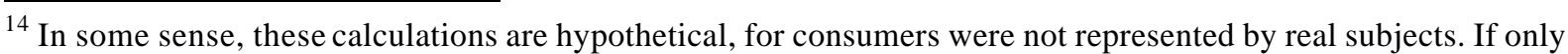
the payoffs of real subjects are considered, efficiency - then the sum of all firms' profit - is maximised if the lowest-cost firm alone produces and it charges the monopoly price given its unit costs.
} 
typically the lower the more firms there are in the market. More aggressive bidding also contributes to higher efficiency.

It is striking that both absolute and relative efficiencies are very close to the figures achieved in the theoretical equilibrium. The binomial test, applied to the difference between observed and predicted surplus in the individual sessions, cannot reject the null hypothesis of no difference at any conventional level. It seems that the efficiency-enhancing effect of more aggressive bidding is just cancelled out by the loss in cost efficiency. Notice that in equilibrium it is always guaranteed that the firm(s) with the lowest costs serve all the demand, whereas this is not always the case in the experimental markets. In fact, in on average 5.25 out of 50 rounds (or $10.5 \%$ ) in duopolies, 6.33 rounds $(12.7 \%)$ in triopolies, and 6.72 rounds $(13.4 \%)$ in tetrapolies at least one firms that does not have the lowest costs produces positive quantities. ${ }^{15}$ Thus, while most of the time the most cost efficient firm(s) serve all the demand, occasional displacements reduce efficiency to the extent that similar surplus levels as in equilibrium are observed, though firms tend to price more aggressively.

Table 6. Average relative total surplus in the individual markets

\begin{tabular}{cccc}
\hline Group No. & $\mathrm{n}=2$ & $\mathrm{n}=3$ & $\mathrm{n}=4$ \\
\hline 1 & $82.37 \%$ & $91.68 \%$ & $93.83 \%$ \\
2 & $82.51 \%$ & $92.14 \%$ & $95.00 \%$ \\
3 & $86.84 \%$ & $92.48 \%$ & $95.67 \%$ \\
4 & $87.56 \%$ & $94.20 \%$ & $95.85 \%$ \\
5 & $87.73 \%$ & $94.85 \%$ & $96.43 \%$ \\
6 & $88.07 \%$ & $95.76 \%$ & $96.75 \%$ \\
7 & $90.25 \%$ & $95.89 \%$ & $97.00 \%$ \\
8 & $91.26 \%$ & $96.02 \%$ & $97.21 \%$ \\
9 & $92.19 \%$ & $97.51 \%$ & $97.32 \%$ \\
10 & $93.65 \%$ & & $98.06 \%$ \\
11 & $96.59 \%$ & & $98.23 \%$ \\
12 & $98.89 \%$ & & \\
\hline Average & $89.83 \%$ & $94.50 \%$ & $96.48 \%$ \\
\hline Equilibrium & $89.09 \%$ & $93.67 \%$ & $95.99 \%$ \\
\hline
\end{tabular}

\subsection{Profits}

To conclude the presentation of our experimental data, we now look at the implications of our findings for firms' profits. Table 7 shows average round profits for the different groups over the 50 rounds of the experiment, ordered from the lowest to the highest for each value of $n$.

\footnotetext{
${ }^{15}$ The difference between treatments is weakly significant $(\mathrm{p}=0.07$ one-sided $)$ for the comparison between $n=2$ and $n=4$. All other pairwise comparisons do not yield a significant result.
} 
The table shows average round profits decreasing with the number of firms. For all pairwise comparisons, Fisher's two-sample randomisation test rejects the null hypothesis of equal average round profits at a significance level lower than $?=0.001$ (one-sided). Thus, our data exhibit a clear and strong tendency towards profits decreasing with $n .^{16}$

As experimental firms tend to charge prices with lower profit margins than predicted by the theoretical equilibrium, profits are considerably lower than would result from equilibrium play.

Table 7. Average profit per round

\begin{tabular}{cccc}
\hline Group No. & $n=2$ & $n=3$ & $n=4$ \\
\hline 1 & 210.9 & 180.3 & 123.2 \\
2 & 321.1 & 180.6 & 128.0 \\
3 & 362.2 & 191.0 & 138.3 \\
4 & 367.6 & 198.0 & 148.2 \\
5 & 385.4 & 231.6 & 151.0 \\
6 & 456.5 & 235.3 & 155.4 \\
7 & 460.9 & 246.2 & 161.8 \\
8 & 472.6 & 246.8 & 163.7 \\
9 & 484.6 & 258.0 & 164.5 \\
10 & 517.8 & & 175.2 \\
11 & 572.9 & & 198.2 \\
12 & 580.7 & & \\
\hline Average & 432.8 & 218.6 & 155.2 \\
\hline Equilibrium & 572.5 & 373.7 & 259.5 \\
\hline
\end{tabular}

\section{Conclusions}

We report on an experiment examining price levels and the relation between these levels and the number of firms in a price competition environment with uncertainty about competitors' costs. Our results show that average market prices are decreasing and that total surplus is increasing in the number of firms; in addition, average market prices stay above marginal cost for different numbers of firms. To this extent, our experimental data back the model proposed by Spulber (1995) as a satisfactory resolution of the Bertrand paradox.

Our experimental data show that if one relaxes the assumption of complete information on rivals' costs, pricing behaviour appears more intuitive than the one in the standard Bertrand game: We observe positive profits which are the higher the fewer competitors there are.

\footnotetext{
${ }^{16}$ Part of this effect can be attributed to the fact that a firm will sell fewer times in larger markets. The average profit in case that the firm does make a non-zero profit is 852.0 in duopolies, 656.4 in triopolies, and 615.9 in tetrapolies. The difference between $n=2$ and either of $n=3$ and $n=4$ is significant at $?=0.01$ (one-sided), the difference between $n=3$ and $n=4$ is not significant.
} 
Competition is still strong, as pricing tends to be even more aggressive than in the strategic equilibrium. This improves consumers' situation, but it does so at a twofold price for producers: They suffer from lower profit margins, and, in addition, from occasional displacements when the producing firm is not the most cost-efficient. With respect to total surplus, consumer benefits and producer losses - as compared with equilibrium - just cancel each other out.

Of course, our results cannot be a conclusive investigation of pricing behaviour in oligopolies with cost uncertainty. To keep things simple, we started with a symmetric framework that does not take differences in the individual firms' characteristics into account. In the wider world, structural asymmetries between firms are common, but they add substantial complexity to the model. Further, we model cost uncertainty in the very stylised way, as random draws independent for each firm and every round. Uncertainty about competitors' costs seems a very natural assumption for reallife oligopolies, but, as costs are determined by factors like technology or input prices, changes may not affect the individual firms in a completely independent manner, neither may they be completely uncorrelated over time. A richer model of price competition under cost uncertainty therefore should allow for cost levels evolving dynamically, and for competitors' costs to be affiliated. We do believe, however, that the insights from this simple setting can contribute to a broader research agenda on oligopolistic competition under uncertainty. 


\section{References}

Abbink, K., and J. Brandts (2002): “24”. CeDEx Discussion Paper, University of Nottingham.

Abbink, K., and A. Sadrieh (1995): "RatImage - Research Assistance Toolbox for Computer-Aided Human Behavior Experiments". SFB Discussion Paper B-325, University of Bonn.

Bertrand, J. (1883): "Théorie Mathématique de la Richesse Sociale", Journal des Savants, 67, 499-508.

Dastidar, K.G. (1995): "On the existence of pure strategy Bertrand equilibrium", Economic Theory, 5, 19-32.

Davis, D. and C. Holt (1994): "Market power and mergers in laboratory markets with posted prices", RAND Journal of Economics, 25, 467-487.

Dufwenberg, M., and U. Gneezy (2000): "Price competition and market concentration: an experimental study", International Journal of Industrial Organization, 18, 7-22.

Dufwenberg, M., U. Gneezy, J. Goeree, and R. Nagel (2002): "Price Floors and Competition”, Working paper, Stockholm University.

Edgeworth, F. (1925): “The pure theory of monopoly”, In Papers Relating to Political Economy, vol. 1, 111142.

Holt, C. (1995): "Industrial Organization: A Survey of Laboratory Research", in: J. Kagel and A. Roth (eds.), The Handbook of Experimental Economics, Princeton University Press, Princeton, N.J., 347-443.

Huck, S., K. Konrad, W. Müller, and H.T. Normann (2002): "Mergers and the perception of market power: An experimental study", Working paper, University College London.

Huck, S., H.T. Normann, and J. Oechssler (1999): "Learning in Cournot Oligopoly--An Experiment", Economic Journal, 109, C80-95.

Huck, S., H.T. Normann, and J. Oechssler (2001): "Two are few and four are many: Number effects in experimental oligopolies". BonnEcon Discussion Paper 12/2001, University of Bonn.

Kagel, J. (1995): “Auctions: A Survey of Experimental Research”, in: J. Kagel and A. Roth (eds.), The Handbook of Experimental Economics, Princeton University Press, Princeton, N.J., 499-585.

Kruse, J., S. Rassenti, S. Reynolds and V. Smith (1994): "Bertrand-Edgeworth Competition in Experimental Markets", Econometrica, 62, 343-372.

Moir, R. (1998): “A Monte Carlo Analysis of the Fisher Randomization Technique: Reviving Randomization for Experimental Economists", Experimental Economics, 1, 87-100.

Morgan, J., H. Orzen, and M. Sefton (2001): “An Experimental Study of Price Dispersion”, CeDEx Working Paper, University of Nottingham.

Offerman, T., J. Potters and J. Sonnemans (2002): "Imitation and Belief Learning in an Oligopoly Experiment", Review of Economic Studies, forthcoming.

Plott, C. , and V. Smith (1978): "An Experimental Examination of Two Exchange Institutions", Review of Economic Studies, 45, 133-153.

Selten, R., and J. Apesteguía (2002): "Experimentally Observed Imitation and Cooperation in Price Competition on the Circle", BonnEcon Discussion Paper 19/2002, University of Bonn.

Spulber, D.F. (1995): "Bertrand Competition when Rivals' Costs are Unknown”, The Journal of Industrial Economics, 43, 1-11.

Vives, X. (1999): “Oligopoly Theory”. MIT Press.

Williams, F. (1973): "The Effect of Market Organization on Competitive Equilibrium: The Multi-unit Case", Review of Economic Studies, 40, 97-113.

Wolfstetter, E. (1997): “Auctions: An introduction”, Journal of Economic Surveys, 10, 367-420. 


\section{Appendix: The Written Instructions $(n=4)$}

(other treatments analogous)

\section{General information}

We thank you for coming to the experiment. The purpose of this session is to study how people make decisions in a particular situation. During the session it is not permitted to talk or communicate with the other participants. If you have a question, please raise your hand and one of us will come to your desk to answer it. During the session you will earn money. At the end of the session the amount you have earned will be paid to you in cash. Payments are confidential, we will not inform any of the other participants of the amount you have earned. In the following, all amounts of money are denominated in talers, the experimental currency unit.

In the experiment you take the role of a firm producing a good. There are four firms serving the market. One firm is you, the other three firms are three other participants you are matched with. You will be matched with the same participants throughout the experiment. In every round, all firms post a price they ask per unit of the good.

The experiment consists of 50 rounds, each structured as follows.

\section{Demand}

The buyers of the good are simulated by the computer. Their behaviour is as follows.

All customers buy only from a firm that offers the lowest price. If two firms ask different prices, they do not buy anything from the firm asking for the higher price.

The buyers are willing to buy the more units the lower the price is. At a price of 99 talers per unit or higher, no units can be sold. For each taler that the price is lower than 99, the demand for the good increases by one unit. Thus, at a price of zero talers, buyers are willing to buy 99 units of the good.

The demand is allocated to the firm(s) offering the lowest price. If more than one firm asks the same price, all firms asking the lowest price are allocated equal shares of the demand for that price.

\section{Costs}

Each unit a firm produces causes a cost to the firm. The cost per unit varies from round to round and is likely to be different for each firm. In particular, the unit costs are drawn randomly at the start of each round, independently for each firm, from all integer numbers between 0 and 99 inclusively, where all numbers are equally likely.

Your total costs are the number of units you produce and sell times the unit costs. There are no fixed costs.

\section{Decisions}

In each round you and the other participants that you are matched to will each separately make a decision. This decision will consist in choosing a price between 0 and 99 . When you have decided on a price please enter it into the computer.

\section{Earnings}

After each round, buyers' demand is computed according to the pattern described above, i.e. the market demand, in units, is 99 minus the lowest price. The firm asking the lowest price produces and sells the market demand. If two or more firms ask the same lowest price, the market demand is shared equally among these firms. 
Your revenue is the number of units you sell times the price you have asked. Your total costs are the number of units you sell times the unit cost that have been drawn randomly for that round. Your round profit is your revenue minus your total costs. Notice that you can make a loss if you ask a price that is lower than your unit costs.

Firms whose price has not been the lowest make a profit of zero.

\section{Payments}

At the beginning of the experiment each of you will receive 3000 talers credited to your talers account. After each round, your round payoffs are credited to your talers account. At any moment during the experiment you will be able to check your talers account on the screen.

Should you accumulate losses such that your taler account is negative, you are bankrupt and cannot continue participating in this experiment.

At the end of the experiment your total payoff in your talers account will be converted into Sterling at the exchange rate of $£ 1$ for every 1000 talers. 